\title{
The Role of Saline Sonohysterography Prior to IVF/ICSI and its Impact on Assisted Reproduction Program Outcome in Egyptian Community
}

\author{
Haitham Torky ${ }^{1 *}$ and Asem Moussa ${ }^{2}$ \\ ${ }^{1}$ Department of Obstetrics and Gynaecology, October 6 University, Egypt \\ ${ }^{2}$ Department of Obstetrics and Gynaecology, Al-Azhar University, Egypt
}

*Corresponding author: Haitham Torky, Department of Obstetrics and Gynaecology, October 6 University, Egypt, Tel: +20100123016, Fax No: +202252400661; E-mail: haithamtorky@yahoo.com

Received date: September 13, 2016; Accepted date: October 18, 2016; Published date: October 24, 2016

Citation: Torky H, Moussa A (2016) The Role of Saline Sonohysterography Prior to IVF/ICSI and its Impact on Assisted Reproduction Program Outcome in Egyptian Community. Reproductive Immunol Open Acc 1:23. doi: 10.21767/ 2476-1974.100023

Copyright: (C) 2016 Torky H, et al. This is an open-access article distributed under the terms of the Creative Commons Attribution License, which permits unrestricted use, distribution, and reproduction in any medium, provided the original author and source are credited.

\begin{abstract}
Aim: To assess the incidence of undiagnosed intrauterine pathology based on saline sonohysterography in women with normal transvaginal ultrasound and their impact on the success rate of Intracytoplasmic sperm injection in Egyptian community.

Patients and methods: Two hundred qualified patients scheduled for first time Intracytoplasmic sperm injection treatment were divided into 2 groups each containing 100 patients. Group 1 did saline sonohysterography and cases with intrauterine lesions were treated by hysteroscopy prior to undergoing Intracytoplasmic sperm injection, while group 2 did Intracytoplasmic sperm injection without prior saline sonohysterography. The main outcome measures were undiagnosed intrauterine abnormalities as uterine anomalies and polyps, in addition to, pregnancy, miscarriage and on-going pregnancy rates.
\end{abstract}

Results: Uterine lesions were found in $35 \%$ of cases undergoing sonohysterography, and 27 out of the 35 cases were treated by hysteroscopy. A significant difference in pregnancy rate and on-going pregnancy rate in favour of the sonohysterography group $(P=0.04)$ and $(P=0.031)$ respectively.

Conclusion: Saline sonohysterography is a non-invasive method for the diagnosis of uterine abnormalities improving the outcome of IVF/ICSI cycles.

\section{Keywords Saline sonohysterography; ICSI outcome;} Egyptian community

\section{Introduction}

The uterus has an important role in reproduction. Between 3 and $10 \%$ of infertile women have uterine factor of infertility, which may disturb sperm ascend and implantation of the fertilized ovum leading to pregnancy loss and other obstetric problems [1]. Hysteroscopy prior to in vitro fertilization (IVF) diagnosed unsuspected intrauterine abnormalities in $11-45 \%$ of cases [2].

Despite advances in assisted reproductive technology (ART) there is a huge gap between a successful embryo transfer and pregnancy rate, which causes both mental and physical burdens to the patients with each IVF cycle, in addition to, the costs associated with the treatment itself [3].

Saline infusion sonohysterography (SIS) is useful in the diagnosis of intrauterine abnormalities and has the advantages of being inexpensive, very accurate and non-invasive test [4]. In spite of this the Royal College of Obstetricians and Gynaecologists (RCOG) neither recommends SIS nor hysteroscopy as an initial investigation prior to IVF [5], however, other more recent studies as those done by $[6,7]$ reported a significant increase in pregnancy rate after the treatment of unsuspected uterine abnormalities, especially the former study which was done in patients with previous 2 failed IVF attempts. Another important difference between UK and Egypt is that the National health services in UK sponsors up to 3 cycles of IVF/ICSI contrary to Egypt were all the cycle costs are covered by the patients, which causes a lot of financial burden especially that most of those patients can barely finance one treatment cycle.

The aim of our study was to assess the incidence of undiagnosed intrauterine pathology based on saline sonohysterography in women with normal transvaginal ultrasound and their impact on the success rate of ICSI in Egyptian community.

\section{Patients and Methods}

The study was a prospective trial conducted in the International Islamic center for population study and researches in Al-Azhar University in Cairo. The study was approved by the ethical committee of Al-Azhar University. Two hundred patients with either primary or secondary infertility scheduled for first time in-vitro fertilization (IVF) and intra-cytoplasmic sperm injection (ICSI) treatment and fulfilling the inclusion criteria, which are age between 25 and 30 years, and having no visible 
intra-cavitary pathology by transvaginal ultrasound done in the late follicular phase signed an informed consent to participate in the study, while patients with abnormal transvaginal ultrasound, presence of endometrioma or ovarian cyst, history of recurrent consecutive miscarriage before 20 weeks gestation, prior hysteroscopy treatment, inter-menstrual blood loss, age below 25 or above 30 years were excluded from the study.

The patients were divided into 2 groups each containing 100 patients. Group 1 did saline sonohysterography prior to undergoing ICSI, while group 2 did ICSI without prior saline sonohysterography.

\section{Technique of saline sonohysterography}

The procedure was done between day 4 and day 11 of the menstrual cycle when no menses were present. A speculum was inserted vaginally and up to $10 \mathrm{ml}$ of sterile saline solution were infused into the uterine cavity through number 8 pediatric Foley's catheter to distend the endometrial cavity and the catheter was fixed with $2 \mathrm{ml}$ of normal saline to become fixed inside the uterus and prevent leakage of saline. A transvaginal transducer (Medisonx6) was used to scan the uterine cavity. The findings were recorded in the patients' files. This procedure costs 200 L.E. (equivalent to 20\$). Cases with lesions found in the uterine cavity were treated by hysteroscopy the following day, which costs 800 L.E. (equivalent to $80 \$$ ), before starting ICSI treatment in the following cycle.

All patients performed ICSI using the standard long protocol with short acting $\mathrm{GnRH}$ agonist (lucrine 10 unites) injected subcutaneously daily from day 21 of the previous menstrual cycle. Human menopausal gonadotropins(HMG) (Merional 75 units) was given in an adjusted dose for each patient daily intramuscular starting at day 2 of the menstrual cycle. Final oocyte maturation was achieved by administrating human chorionic gonadotropins (HCG) when 3 or more follicles of more than $18 \mathrm{~mm}$. were present. Oocyte retrieval was carried out 34-36 hours after HCG administration. The average cost of ICSI cycle was 12000 L.E. (equivalent to 1200 \$).

The main outcome measures were undiagnosed intrauterine abnormalities as uterine anomalies and polyps, in addition to, pregnancy, miscarriage and ongoing pregnancy rates.

\section{Results}

The demographic data: age, weight and body mass index are shown in Table 1. As regards the type of infertility there were 71 cases with primary infertility (71\%) and 29 cases with secondary infertility (29\%) in group 1 as compared to 70 cases with primary infertility (70\%) and 30 cases with secondary infertility (30\%) in group 2 (P-value $=>0.05)$. The duration of infertility ranged between 1 and 6 years in both groups with a mean of 3.16 and a standard deviation of $+/-2.03$ in group 1 , and a mean of 3.22 and a standard deviation of $+/-1.9$ in group $2(P$-value $=0.850)$.

The baseline characteristics: anti-Mullerian hormone (AMH) level, basal follicle stimulating hormone (FSH) level, number of HMG ampoules required per cycle, endometrial thickness at the day of ovum pick-up or number of follicles $18 \mathrm{~mm}$. or more are shown in Table 2. There were no recorded cases of complications or procedure failure in this study. The distribution of intrauterine lesions found in the saline sonohysterography group is shown in Table 3 . Saline sonohysterography had a sensitivity of $91.11 \%$, specificity of $88.1 \%$, and positive predictive value of $89.3 \%$, negative predictive value of $90.7 \%$ and a diagnostic accuracy of 91\% (Confidence Interval 95\% for all these values). Positive likelihood ratio was 8.65 and negative likelihood ratio was 0.04 . Pregnancy rate, miscarriage rate and on-going pregnancy rate in both groups are shown in Table 4.

Table 1: Showing the demographic data in both groups, SD= Standard deviation. $\mathrm{n}=$ number of cases. Kg=Kilograms. $\mathrm{BMI}=$ Body mass index.

\begin{tabular}{|c|c|c|c|c|c|c|}
\hline & $\begin{array}{l}\text { Group } \\
1 \\
(n=100)\end{array}$ & $\begin{array}{l}\text { Group } \\
1\end{array}$ & $\begin{array}{l}\text { Group } \\
2 \\
(n=100)\end{array}$ & Group 2 & $\mathrm{~T}$ & P-value \\
\hline & Range & $\begin{array}{l}\text { Mean } \\
+/- \text { SD }\end{array}$ & Range & $\begin{array}{l}\text { Mean +/- } \\
\text { SD }\end{array}$ & & \\
\hline $\begin{array}{l}\text { Age } \\
\text { (years) }\end{array}$ & $25-30$ & $\begin{array}{l}26.8 \\
+/- \\
3.54\end{array}$ & $25-30$ & $\begin{array}{l}27.11 \quad+/- \\
3.16\end{array}$ & $\begin{array}{l}0.7 \\
15\end{array}$ & 0.6732 \\
\hline $\begin{array}{l}\text { BMI } \\
\left(\mathrm{kg} / \mathrm{m}^{2}\right)\end{array}$ & $18-39.4$ & $\begin{array}{l}29.39 \\
+/- \\
5.68\end{array}$ & $\begin{array}{l}17.9-41 \\
.1\end{array}$ & $\begin{array}{l}28.8 \quad+/- \\
5.47\end{array}$ & $\begin{array}{l}0.7 \\
482\end{array}$ & 0.4552 \\
\hline
\end{tabular}

Table 2: Showing the baseline clinical characteristics of both groups; $\mathrm{AMH}=$ Anti-Mullerian hormone. $\mathrm{FSH}=$ Follicle stimulating hormone. HMG=Human menopausal gonadotrophin.

\begin{tabular}{|l|l|l|l|}
\hline Parameters & $\begin{array}{l}\text { Group 1 (Mean +/- } \\
\text { SD) }\end{array}$ & $\begin{array}{l}\text { Group 2 (Mean +/- } \\
\text { SD) }\end{array}$ & P-value \\
\hline AMH (pmol/liter) & $4.43+/-0.12$ & $4.41+/-0.14$ & 0.2794 \\
\hline $\begin{array}{l}\text { Basal FSH } \\
(\mathrm{mIU} / \mathrm{ml})\end{array}$ & $4.7+/-0.9$ & $4.6+/-1.1$ & 0.4825 \\
\hline $\begin{array}{l}\text { HMG ampoules } \\
\text { per cycle }\end{array}$ & $4.9+/-1.3$ & $4.7+/-2.1$ & 0.4190 \\
\hline $\begin{array}{l}\text { Endometrial } \\
\text { thickness }\end{array}$ & $7.9+/-1.3$ & $8.1+/-1.2$ & 0.2596 \\
\hline $\begin{array}{l}\text { Number of } \\
\text { follicles 18 mm. } \\
\text { or more }\end{array}$ & $3.8+/-1.1$ & $3.5+/-1.6$ & 0.1239 \\
\hline
\end{tabular}

Table 3: Showing the diagnosis of the lesions detected in group 1 which performed saline sonohysterography.

\begin{tabular}{|l|l|l|}
\hline Diagnosis & $\begin{array}{l}\text { Saline sonohysterography } \\
\text { diagnosis (number of patients) }\end{array}$ & Hysteroscopy \\
\hline Normal uterus & 65 & Not done \\
\hline Submucus fibroid & 5 & $4(80 \%)$ \\
\hline Endometrial polyp & 10 & $10(100 \%)$ \\
\hline Adenomyosis & 6 & Not done \\
\hline Uterine malformations & 6 & $6(100 \%)$ \\
\hline Adhesions & 8 & $7(87.5 \%)$ \\
\hline Total & 100 & 27 \\
\hline
\end{tabular}

This article is available from: http://dx.doi.org/10.21767/2476-1974.100023 
P-value

$<0.001$

Table 4: Showing the pregnancy, miscarriage and on-going pregnancy rate in both groups.

\begin{tabular}{|l|c|c|c|c|c|}
\hline Parameters & $\begin{array}{l}\text { Group 1 } \\
\text { (Study } \\
\text { group) }\end{array}$ & $\begin{array}{l}\text { Group 1 } \\
\text { (Study } \\
\text { group) }\end{array}$ & $\begin{array}{l}\text { Group } \\
\text { (Control } \\
\text { group) }\end{array}$ & $\begin{array}{l}\text { Group } \\
2 \\
\text { (Contr } \\
\text { ol } \\
\text { group) }\end{array}$ & P-value \\
\hline Number & $\%$ & Number & $\%$ & 0.044 \\
\hline $\begin{array}{l}\text { Pregnancy } \\
\text { rate }\end{array}$ & 48 & $48 \%$ & 33 & $33 \%$ & 0.153 \\
\hline $\begin{array}{l}\text { Miscarriage } \\
\text { rate }\end{array}$ & 11 & $11 \%$ & 18 & $18 \%$ & 0.031 \\
\hline $\begin{array}{l}\text { Ongoing } \\
\text { pregnancy } \\
\text { rate }\end{array}$ & 37 & $37 \%$ & 15 & $15 \%$ & \\
\hline
\end{tabular}

\section{Discussion}

Both the uterine cavity and the fallopian tubes have active roles in several reproductive functions, for example, ovum retrieval and transportation, sperm transportation and capacitation, fertilization, embryo nourishing and transportation, in addition to, implantation [8]. Therefore, it is important to evaluate both the uterine cavity and the fallopian tubes, which represents one third of the costs of management of the infertile couple [9].

Transvaginal ultrasound is a popular method in the initial assessment of infertile couples; however, it has its limitation in detecting small nodular lesions with similar echogenicity to the endometrium [10]. Saline sonohysterography has the advantages of being quick, easy, safe and well tolerated method for assessing both the uterine cavity and the fallopian tubes [11], in addition to, 96\% agreement with hysteroscopy in the diagnosis of growing focal lesions in the study done by [12].

The current study had no significant difference between both groups as regards the demographic data of the patients (Table 1), $\mathrm{AMH}$ and basal FSH levels, number of HMG ampoules required per cycle, endometrial thickness at the day of ovum pick-up or number of follicles $18 \mathrm{~mm}$. or more (Table 2). The type and duration of infertility didn't differ significantly between both groups, however, we found uterine lesions in 35 cases (35\%) of group 1, of which 27 cases $(27 \%)$ were treated by hysteroscopy, this was highly significant $(\mathrm{P}<0.001)$ (Table 3$)$ and resulted in a significant difference in both pregnancy and ongoing pregnancy rates (Table 4 ) the latter results agreed with the results of the study done by [6] who found $9-13 \%$ increase in clinical pregnancy rate in the following IVF cycle in patients who had previous 2 failed IVF attempts after treating their intrauterine lesions. Although the current study recruited patients undergoing ICSI for the first time we think that the financial costs which is totally covered by our patients is an important factor to take into consideration, taking into account that the costs of sonohyterography is $20 \$$ and hysteroscopy if needed is $80 \$$ are together a lot less than that of a failed ICSI cycle (1200\$). This point should be taken into account when counselling the patients regarding treatment options, expected cycle fecundity and treatment cost.

The current study showed $91.11 \%$ sensitivity, $89.3 \%$ positive predictive value and $91 \%$ diagnostic accuracy, which is near the values found by [13] who found $93.3 \%$ sensitivity, $94.6 \%$ positive predictive value and $93.3 \%$ diagnostic accuracy in detection of endometrial polyps, and less than the study done by [14] who found $100 \%$ sensitivity in detection of the same type of lesion.

Procedural failure of sonohysterography is reported to be between 2.9 and $6 \%$ [15] and [16], however, we had no cases of procedural failure a possible explanation for this is that all the patients were premenopausal with cervices easy to catheterize. Dueholm and co-workers [17], reported $1 \%$ infection rate following sonohysterography, however, we had neither infected cases nor other complications in the current study.

Endometrial local injury is another controversial point, while some studies as [18] concluded that local endometrial injury increased the pregnancy rate other studies as that done by [19] concluded the opposite. The current study showed that the pregnancy rate was increased in the group that had local endometrial injury by the sonohysterography procedure.

The current study is not without limitations as certain points were not discussed as the patient's preference, discomfort and the time spent. Studies addressing these points are small and future work is needed to address these areas.

\section{Conclusion}

Saline sonohysterography is a non-invasive method for the diagnosis of uterine abnormalities and tubal patency improving the outcome of ICSI cycles. Saline sonohysterography is a simple, safe and inexpensive procedure avoiding aesthetic complications and has rare adverse effects.

\section{References}

1. Hatasaka $H$ (2011) Clinical management of the uterine factor in infertility. Clin Obstet Gynecol 54: 696-709.

2. Markrakis E, Pantos K (2010) The outcomes of hysteroscopy in women with implantation failures after in-vitro fertilization: Findings and effect on subsequent pregnancy rates. Curr Opin Obstet Gynecol 22: 339-343.

3. Bouwmans CA, Linsten BM, Eijkemans MJ, Habbema JD, Braat DD, et al. (2008) A detailed cost analysis of in vitro fertilization and intracytoplasmic sperm injection treatment. Fertil Steril 89: 331-341.

4. Ludwin A, Ludwin I, Banas T, Knafel A, Miedzyblocki M, et al. (2011) Diagnostic accuracy of sonohysterography, hysterosalpingography and diagnostic hysteroscopy in diagnosis of arcuate, septate and bicornuate uterus. J Obstet Gynecol Res 37: 178-186.

5. Royal College of Obstetricians and Gynaecologists (2004) Fertility assessment and treatment for people with fertility problems.

6. Rama Raju GA, Shashi Kumari G, Krishna KM, Prakash GJ, Madan K (2006) Assessment of uterine cavity by hysteroscopy in assisted reproduction program and its influence on pregnancy outcome. Arch Gynecol Obstet 274: 160-164. 
7. Gera PS, Allemand MC, Tatpati LL, Galanits TM, Morbeck D, et al. (2008) Role of saline infusion sonography in uterine evaluation before frozen embryo transfer cycle. Fertil Steril 89: 562-566.

8. Patil M (2009) Assessing tubal damage. J Hum Reprod Scien2: 2-11.

9. Severi FM, Bocchi C, Florio P, Cobellis L, La Rosa R, et al. (2011) Hysterosalpingography vs Hysteroscopy vs Hydrosonography. Fertil Steril 96: 349-352.

10. Laifer-Narin S, Ragavendra N, Parmenter EK, Grant EG (2002) False normal appearance of the endometrium on conventional transvaginal sonography: comparison with saline hysterosonography. Am J Roentgenol 178: 129-133.

11. Saunders RD, James M, Shwayder JD, Nakazima ST (2011) Current methods of tubal patency assessment. Fertil Steril 95: 2171-2179.

12. Epstein E, Ramirez A, Skoog L, Valentin L (2001) Transvaginal sonography, saline contrast sonohysterography and hysteroscopy for the investigation of women with postmenopausal bleeding and endometrium $>5 \mathrm{~mm}$. Ultrasound Obstet Gynecol 18: 157-162.

13. Kamel HS, Darwish AM, Mohamed SA (2000) Comparison of transvaginal ultrasonography and vaginal sonohysterography in the detection of endometrial polyps. Acta Obstet Gynecol Scand 79: 60-64.
14. Nanda S, Chadha N, Sen J, Sangwan K (2002) Transvaginal sonography and saline infusion sonohysterography in the evaluation of abnormal uterine bleeding. Aust NZ J Obstet Gynaecol 42: 530-534.

15. Lev-Toof A, Toaf ME, Liv JB, Merton DA, Goldberg BB (1996) Value of sonohysterography in the diagnosis and management of abnormal uterine bleeding. Radiology 201: 179-184.

16. Schwarzler $\mathrm{P}$, Conci $\mathrm{H}$, Bosch $\mathrm{H}$, Berlinger $\mathrm{A}$, Wohlgenannt $\mathrm{K}$, et al. (1998) An evaluation of sonohysterography and diagnostic hysteroscopy for the assessment of intrauterine pathology. Ultrasound Obstet Gynecol 11: 337-342.

17. Dueholm M, Forman A, Jensen ML, Laursen H, Karacht P (2001) Transvaginal sonography combined with saline contrast sonohysterogram in evaluating the uterine cavity in premenopausal patients with abnormal uterine bleeding. Ultrasound Obstet Gynecol 18: 54-61.

18. Barash A, Dekel N, Fieldust S, Segal I, Schechtman E, et al. (2003) Local injury to the endometrium doubles the incidence of successful pregnancies in patients undergoing in vitro fertilization. Fertil Steril 79: 1317-1322.

19. Karimzade MA, Oskouian H, Ahmadi S, Oskouian L (2010) Local injury to the endometrium on the day of oocyte retrieval has a negative impact on implantation in assisted reproductive cycles: a randomized controlled trial. Arch Gynecol Obstet 281: 499-503. 